\title{
Risk Evaluation of Bidding for Wind Farm Construction Project
}

\author{
Yonghua Wang ${ }^{1}$, Guosheng $\mathrm{Hu}^{2}$ \& Jia-xin Zhang ${ }^{1}$ \\ ${ }^{1}$ School of Economics and Management, North China Electric Power University, Beijing 102206, China \\ ${ }^{2}$ Jiangxi Electric Power Trading Center Co. Ltd., China \\ Correspondence: Yonghua Wang, School of Economics and Management, North China Electric Power University, \\ Beijing 102206, China. Tel: 86-137-0709-3159. E-mail: 446836810@qq.com
}

Received: December 18, 2018

Accepted: January 17, 2019

Online Published: May 30, 2019

doi:10.5539/eer.v9n1p71

URL: https://doi.org/10.5539/eer.v9n1p71

The research is financed by Beijing Social Science Fund Energy Base Project "A Study on Clean Utilization and Development of Energy in Rural Area under Beijing-Tianjin-Hebei Coordinated Development" (17JDYJB011).

\begin{abstract}
With the rapid development and growth of the installed capacity of wind power generation in China, more and more attention has been paid to the risk of wind farm construction projects. Based on the extension element method and the multi-level fuzzy comprehensive evaluation method, this paper makes an empirical analysis on the bidding risk of the wind farm construction project of Xintiandi energy company in Hebei province. The research shows that the extensible matter element method can provide effective support for decision makers because there are no different evaluation principles and more accurate risk evaluation.
\end{abstract}

Keywords: bidding, risk, construction, wind farm, comprehensive evaluation method

\section{Introduction}

Since 2005, China's wind power installed capacity has been growing. At the end of 2017, China wind power added installed capacity of 18,190MW, the cumulative Installed capacity of 163,250MW (Figure 1)[1], for 6 consecutive years ranked first in the world. In the 2017, wind power generation accounted for about $4.7 \%$ of the country's electricity generation. 2018 1-September, the national Wind power infrastructure new power generation production capacity $12,610 \mathrm{mw}$; wind power completed investment of 34.6 billion yuan.

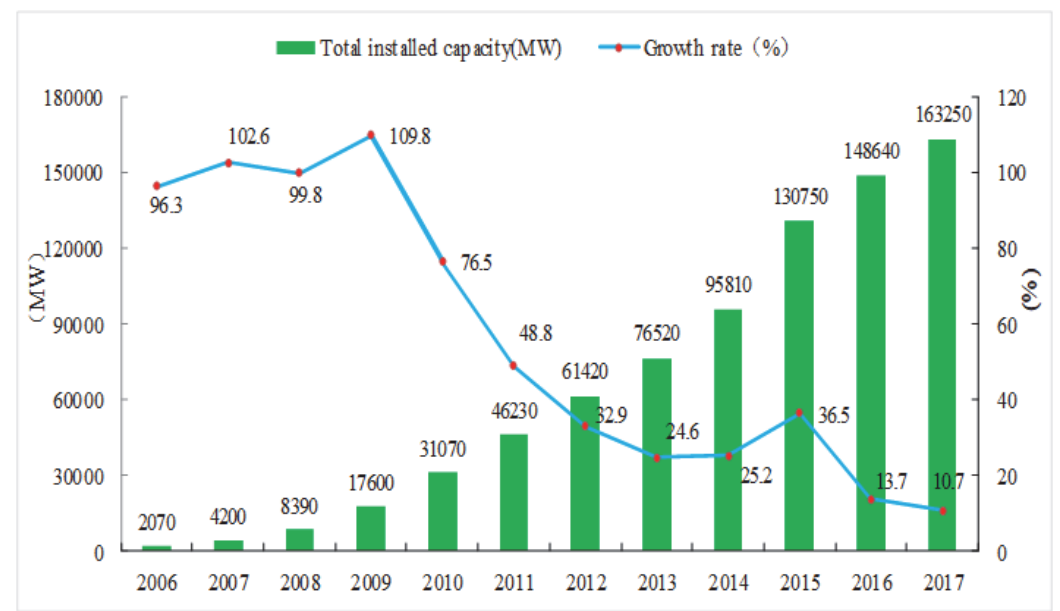

Figure 1. Development of China's wind power installed capacity in the 2006-2017

With the continuous expansion of wind power installed capacity, the risks faced by wind farm construction projects in China have been paid more and more attention. How to accurately identify the bidding risk of wind farm construction project, and reasonably formulate an effective bidding risk management strategy is 
an important content of wind farm construction and management. This paper mainly discusses the risk factors of bidding for wind farm construction projects in China, establishes the comprehensive evaluation index system of bidding risk of wind farm construction project, and takes the wind farm construction project of Hebei Xintiandi Energy company as a case, and uses the extension element method to evaluate the bidding risk comprehensively.

\section{Model}

\subsection{Construction of Risk Evaluation Index System for Bidding and Bidding of Wind Farm Construction Project}

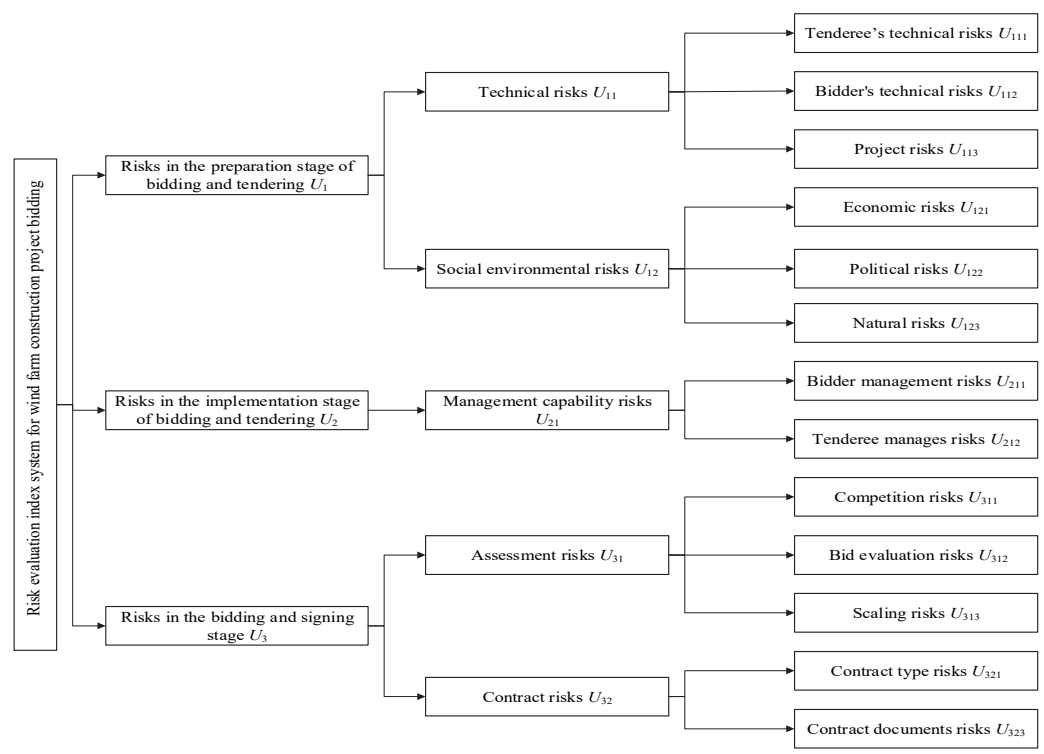

Figure 2. Comprehensive evaluation index system of bidding risk of wind farm construction project

Based on the empirical analysis of the risk data of wind farm construction projects at home and abroad, referring to the relevant research literature[2-3], combined with the analysis of the results of interviews with engineering managers and bidders, the index factors affecting the bidding risk of wind farm construction projects are preliminarily determined, and on this basis, senior project management experts are consulted to apply the Law (Delphi) The risk factors of bidding for wind farm construction project are modified and supplemented, and the risk evaluation Index system of bidding for wind farm construction project is obtained (see Figure 2). The system consists of 5 level three indexes, such as Risk Index (U1), risk index of bidding implementation stage (U2) and Risk Index (U3) of calibration contract stage, 3 level two index, technical risk, social environment risk, management ability risk, evaluation target risk and contract risk, and 13 level four index.

\subsection{Analysis and Calculation Ideas and Models of Extensible Matter Element Method}

Because the bidding process of wind power plant construction project is affected by many factors, there must be some incompatibility between these risk indexes, which is often neglected by the previous research, or not well solved, therefore, it is necessary to establish a mathematical model that can accurately describe the relationship between the various influencing factors, this is a comprehensive evaluation of the risk of bidding for wind farm construction projects. In order to solve the incompatibility between the evaluation indexes in the bidding risk evaluation system of wind power plant construction project, this paper adopts the theory of extension matter element analysis, takes the risk grade, evaluation index and eigenvalue of the bidding of wind farm construction project as the matter element, and establishes the multistage matter element model.

The basic principle of extensible element method is: First, based on the existing data situation, the evaluated object is divided into several levels, and the data value range of each level is determined based on the expert opinion or the data composition in the database, and secondly, the index value of the evaluated object is added to the data collection of each level specified above. Based on this step, the evaluation index is analyzed and evaluated, and finally, the correlation degree between the evaluation index value and each level set is compared, according to the size of the correlation degree, if the correlation degree between the two is greater, it means that the degree of compliance between the index and its hierarchical set is the better. The concrete steps are shown in figure 3 : 


\begin{tabular}{|c|c|c|c|}
\hline $\begin{array}{c}\text { Construct the matter-element of } \\
\text { classical domain, section domain } \\
\text { and bidding risk }\end{array}$ & $\begin{array}{l}\text { Determine the weight of risk } \\
\text { evaluation indexes of bidding } \\
\text { at all levels }\end{array}$ & $\begin{array}{l}\text { Set up the correlation function, } \\
\text { calculate the value of the } \\
\text { correlation function }\end{array}$ & To determine the level of risk \\
\hline
\end{tabular}

Figure 3. Concrete steps for comprehensive evaluation of extensible matter element

In this paper, the risk of bidding is divided into 5 levels by using the extension element method to evaluate the bidding risk of wind farm construction projects: Very large, large, general, small, very small, respectively, expressed by $\mathrm{N}_{\mathrm{i}}(\mathrm{i}=1,2,3,4,5)$.

1) Build a classic domain, mainly for level four indicators.

$$
R_{j}=\left(N_{j}, c_{i}, v_{j i}\right)=\left[\begin{array}{ccc}
N_{j} & c_{1} & v_{j 1} \\
& c_{2} & v_{j 2} \\
& \vdots & \vdots \\
& c_{n} & v_{j n}
\end{array}\right]=\left[\begin{array}{ccc}
N_{j} & c_{1} & <a_{j 1}, b_{j 1}> \\
& c_{2} & <a_{j 2}, b_{j 2}> \\
& \vdots & \vdots \\
& c_{n} & <a_{j n}, b_{j n}>
\end{array}\right]
$$

In the formula, the $R_{j}$ represents the $j$-th of the $R$, the $N_{j}$ represents the grade $j$ of the thing, $c_{i}$ represents the $\mathrm{i}$-th feature of the Thing, $\mathrm{v}_{\mathrm{ji}}$ represents $\mathrm{N}_{\mathrm{j}}$ 's range of values for $\mathrm{c}_{\mathrm{i}}$, that is, the classical domain is determined.

2) Build section domains

The level of the bidding risk is all about the range of values for all features.

$$
R_{j}=\left(N_{j}, c_{i}, v_{j i}\right)=\left[\begin{array}{ccc}
N_{j} & c_{1} & v_{j 1} \\
& c_{2} & v_{j 2} \\
& \vdots & \vdots \\
& c_{n} & v_{j n}
\end{array}\right]=\left[\begin{array}{ccc}
N_{j} & c_{1} & <a_{j 1}, b_{j 1}> \\
& c_{2} & <a_{j 2}, b_{j 2}> \\
\vdots & \vdots \\
& c_{n} & <a_{j n}, b_{j n}>
\end{array}\right]
$$

In the formula, $p$ represents the full level of bidding risk, that is, the whole level of the object to be evaluated, $v_{p i}$ represents the range of $\mathrm{p}$ 's value for $c_{i}$, that is, the section domain is determined.

3) Establish the matter-element of bidding risk

The object to be evaluated in this paper is the bidding risk of wind farm construction project, therefore, the matter element of bidding risk is indicated as formula(3).

$$
\mathrm{R}_{0}=\left[\begin{array}{ccc}
\mathrm{p}_{0} & \mathrm{c}_{1} & \mathrm{v}_{1} \\
& \mathrm{c}_{2} & \mathrm{v}_{2} \\
& \vdots & \vdots \\
& \mathrm{c}_{\mathrm{n}} & \mathrm{v}_{\mathrm{n}}
\end{array}\right]
$$

In the formula, $\mathrm{R}_{0}$ represents the matter element of bidding risk, $c_{i}$ represents the $\mathrm{i}$-th characteristic of bidding risk, $v_{\mathrm{i}}$ represents the specific data obtained by $\mathrm{p}_{0}$ on $\mathrm{c}_{\mathrm{i}}$.

4) Determining the weight of risk evaluation index of bidding at all levels

In this paper, we use the sequential relation method to empower the 3 level two indexes included in the Risk evaluation index system of wind farm construction project, and use the eigenvalue method to empower the three level index of the risk evaluation Index system of wind farm construction project bidding, The weight coefficient of the four-level index of the risk evaluation Index system of wind farm construction project is calculated by using the Set value iteration method, the calculation is simple and intuitive, the computation is doubled, and the shortcoming of AHP method is overcome, which is limited by the number of indexes.

5) Establish an association function to calculate the value of the associated function

An association function is established between the various indicators of bidding risk and each level level, and the associated function value is represented as shown in (4).

$$
\mathrm{K}_{\mathrm{j}}\left(\mathrm{V}_{\mathrm{i}}\right)=\left\{\begin{array}{c}
\frac{-\rho\left(\mathrm{v}_{\mathrm{i}}, \mathrm{V}_{\mathrm{ji}}\right)}{\left|\mathrm{V}_{\mathrm{ji}}\right|}, \mathrm{V}_{\mathrm{i}} \in \mathrm{V}_{\mathrm{ji}} \\
\frac{\rho\left(\mathrm{v}_{\mathrm{i}}, \mathrm{V}_{\mathrm{ji}}\right)}{\rho\left(\mathrm{v}_{\mathrm{i}}, \mathrm{V}_{\mathrm{pi}}\right)-\rho\left(\mathrm{v}_{\mathrm{i}}, \mathrm{V}_{\mathrm{ji}}\right)}, \mathrm{v}_{\mathrm{i}} \notin \mathrm{V}_{\mathrm{ji}}
\end{array}\right.
$$


In the formula, $\mathrm{K}_{\mathrm{j}}\left(\mathrm{v}_{\mathrm{i}}\right)$ indicates that the $\mathrm{i}$-th risk evaluation index in the risk evaluation index system of bidding is the correlation function value of the risk level, , and $\rho\left(v_{i}, V_{i i}\right)$ indicates the distance between the matter element value and its classical domain of the risk Evaluation index of the $\mathrm{i}$-th bid. $\left|\mathrm{V}_{\mathrm{ji}}\right|$ indicated that the first bid risk evaluation indicator for the distance of the classical domain of the $\mathrm{j}$ risk level,,$\rho\left(\mathrm{v}_{\mathrm{i}}, \mathrm{V}_{\mathrm{pi}}\right)$ indicated the distance between the matter element value of the i-th bid risk evaluation index and its section domain.

Therefore, the correlation degree of each level of bidding risk to be evaluated is indicated as shown in formula(5).

$$
\mathrm{K}_{\mathrm{j}}\left(\mathrm{p}_{0}\right)=\sum^{\mathrm{n}} \omega_{\mathrm{i}} \mathrm{K}_{\mathrm{j}}\left(\mathrm{v}_{\mathrm{i}}\right)
$$

6) To determine the risk level

When $\mathrm{K}_{\mathrm{j}}\left(\mathrm{p}_{0}\right)$ satisfies formula(6), the bidding risk element $\mathrm{p}_{0}$ belongs to the $\mathrm{j}$ risk level.

$$
\mathrm{K}_{\mathrm{j}}\left(\mathrm{p}_{0}\right)=\max \left\{\mathrm{K}_{\mathrm{j}}\left(\mathrm{p}_{0}\right)\right\} \quad \mathrm{j}=1,2, \cdots \cdots, \mathrm{m}
$$

\section{Case Analysis}

Taking the construction project of Xintiandi wind farm in Hebei energy company as an example, this paper applies the above method and theory of bidding risk identification, and uses the extension element method to evaluate the bidding risk of this project synthetically.

Based on the expert's empirical analysis of the risk of bidding for wind farm construction projects, this paper considers the risk factors that may appear in the course of bidding work in the future, as well as the importance of different bidding stages, and determines the ratio of the risk index $\left(U_{3}\right)$ to the risk Index $\left(U_{1}\right)$ in the preparation stage of bidding for the bidding stage is 1.2. The ratio of the risk index $\left(U_{2}\right)$ to the risk Index $\left(U_{3}\right)$ in the bidding stage is 1.1 , so the weight of the 3 second level risks can be obtained according to the formula of calculating the weight by the sequential relation method, as shown in the specific values as formula(7).

$$
\mathrm{A}_{0}=(0.28,0.38,0.34)
$$

The sum results of the columns of the third level indicator judging matrix, based on the opinions of individual experts, as well as the weights of each indicator, are shown in table 1 .

Table 1. Weight of third level index for bidding risk evaluation of wind farm construction projects based on column and inversion

\begin{tabular}{cccc}
\hline \multirow{2}{*}{ Columns } & Each column summation result & $\boldsymbol{c}_{\boldsymbol{j}}$ & $\boldsymbol{w}_{\boldsymbol{j}}$ \\
\hline 1 & $15 / 2$ & $2 / 15$ & 0.615 \\
2 & 12 & $1 / 12$ & 0.385 \\
3 & $10 / 3$ & $3 / 10$ & 1.000 \\
4 & $37 / 12$ & $12 / 37$ & 0.678 \\
5 & $13 / 2$ & $2 / 13$ & 0.322 \\
\hline
\end{tabular}

The 10 experts invited were required to select the 13 indicators, each of which selected 10 more important indicators and received a level four indicator weight as shown in table 2.

\begin{tabular}{|c|c|c|c|c|c|c|c|c|c|c|c|c|c|}
\hline Expert & $U_{111}$ & $U_{112}$ & $U_{113}$ & $U_{121}$ & $U_{122}$ & $U_{123}$ & $U_{211}$ & $U_{212}$ & $U_{311}$ & $U_{312}$ & $\frac{U_{313}}{1}$ & $\frac{U_{321}}{1}$ & $U_{322}$ \\
\hline $\begin{array}{l}1 \\
2\end{array}$ & 1 & $\begin{array}{l}1 \\
1\end{array}$ & $\begin{array}{l}1 \\
1\end{array}$ & 1 & 1 & $\begin{array}{l}1 \\
1\end{array}$ & $\begin{array}{l}1 \\
1\end{array}$ & $\begin{array}{l}1 \\
1\end{array}$ & & & $\begin{array}{l}1 \\
1\end{array}$ & & 1 \\
\hline 3 & 1 & 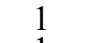 & 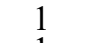 & 1 & & 1 & 1 & 1 & & 1 & & 1 & 1 \\
\hline 4 & 1 & 1 & 1 & & 1 & 1 & & 1 & 1 & 1 & 1 & & 1 \\
\hline 5 & & 1 & 1 & 1 & & 1 & 1 & 1 & 1 & 1 & & 1 & 1 \\
\hline 6 & 1 & 1 & & 1 & 1 & 1 & 1 & 1 & & 1 & 1 & & 1 \\
\hline 7 & 1 & 1 & 1 & 1 & & 1 & 1 & 1 & & 1 & & 1 & 1 \\
\hline 8 & 1 & 1 & 1 & & 1 & 1 & 1 & 1 & & 1 & 1 & & 1 \\
\hline 9 & 1 & 1 & & 1 & 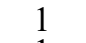 & 1 & 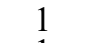 & 1 & & 1 & 1 & & \\
\hline 10 & 1 & & 1 & & 1 & & 1 & 1 & 1 & & & 1 & \\
\hline $\begin{array}{l}\text { total } \\
\text { weight }\end{array}$ & $\begin{array}{c}8 \\
0.32\end{array}$ & $\begin{array}{c}9 \\
0.36\end{array}$ & $\begin{array}{c}8 \\
0.32\end{array}$ & $\begin{array}{c}7 \\
0.30\end{array}$ & $\begin{array}{c}6 \\
0.26\end{array}$ & $\begin{array}{c}10 \\
0.44\end{array}$ & $\begin{array}{c}9 \\
0.47\end{array}$ & $\begin{array}{c}10 \\
0.53\end{array}$ & $\begin{array}{c}3 \\
0.16\end{array}$ & $\begin{array}{c}10 \\
0.53\end{array}$ & $\begin{array}{c}6 \\
0.31\end{array}$ & $\begin{array}{c}5 \\
0.36\end{array}$ & $\begin{array}{c}9 \\
0.64\end{array}$ \\
\hline
\end{tabular}

Table 2. The weight of forth level index of bidding risk evaluation of wind farm construction project based on set value iteration method 
Based on the weight coefficients of the above calculated indexes, the weight coefficient of the forth level index relative to the overall evaluation of bidding risk can be obtained, as shown in formula (8).

$$
\begin{aligned}
& A=(0.055,0.062,0.055,0.032,0.028,0.047,0.179 \text {, } \\
& 0.201,0.037,0.122,0.071,0.039,0.070 \text { ) }
\end{aligned}
$$

Because the evaluation index value of the bidding risk of the wind farm construction project is within the classical domain range of 5 risk levels, the correlation degree is calculated directly according to the formula (4), as shown in table 3.

Table 3. Correlation degree of bidding risk level of wind farm construction project

\begin{tabular}{ccccccc}
\hline Indicators & Characteristic & $\begin{array}{c}\text { Very large } \\
\boldsymbol{K}_{\boldsymbol{1}}\left(\boldsymbol{v}_{\boldsymbol{i}}\right)\end{array}$ & $\begin{array}{c}\text { large } \\
\boldsymbol{K}_{\mathbf{2}}\left(\boldsymbol{v}_{\boldsymbol{i}}\right)\end{array}$ & $\begin{array}{c}\text { general } \\
\boldsymbol{K}_{\mathbf{3}}\left(\boldsymbol{v}_{\boldsymbol{i}}\right)\end{array}$ & $\begin{array}{c}\text { small } \\
\boldsymbol{K}_{\mathbf{4}}\left(\boldsymbol{v}_{\boldsymbol{i}}\right)\end{array}$ & $\begin{array}{c}\text { very small } \\
\boldsymbol{K}_{\mathbf{5}}\left(\boldsymbol{v}_{\boldsymbol{i}}\right)\end{array}$ \\
\hline $\boldsymbol{U}_{\mathbf{1 1}}$ & $c_{1}$ & -0.40 & 0.00 & 0.00 & -0.40 & -0.57 \\
$\boldsymbol{U}_{\boldsymbol{1 1}}$ & $c_{2}$ & -0.33 & 0.50 & -0.33 & -0.60 & -0.71 \\
$\boldsymbol{U}_{\boldsymbol{1 1}}$ & $c_{3}$ & -0.50 & -0.50 & -0.75 & -0.83 & -0.88 \\
$\boldsymbol{U}_{\mathbf{1 2}}$ & $c_{4}$ & -0.25 & 0.50 & -0.25 & -0.50 & -0.63 \\
$\boldsymbol{U}_{\mathbf{1 2}}$ & $c_{5}$ & -0.25 & 0.50 & -0.25 & -0.50 & -0.63 \\
$\boldsymbol{U}_{\mathbf{1 2}}$ & $c_{6}$ & -0.33 & 0.00 & 0.00 & -0.33 & -0.50 \\
$\boldsymbol{U}_{21}$ & $c_{7}$ & -0.33 & 0.50 & -0.33 & -0.60 & -0.71 \\
$\boldsymbol{U}_{\mathbf{2 1}}$ & $c_{8}$ & -0.40 & 0.00 & 0.00 & -0.40 & -0.57 \\
$\boldsymbol{U}_{31}$ & $c_{9}$ & 0.00 & 0.00 & -0.50 & -0.67 & -0.75 \\
$\boldsymbol{U}_{\mathbf{3 1}}$ & $c_{10}$ & -0.43 & -0.20 & 0.50 & -0.20 & -0.43 \\
$\boldsymbol{U}_{31}$ & $c_{11}$ & -0.40 & 0.00 & 0.00 & -0.40 & -0.57 \\
$\boldsymbol{U}_{\mathbf{3 2}}$ & $c_{12}$ & -0.43 & -0.20 & 0.50 & -0.20 & -0.43 \\
$\boldsymbol{U}_{\mathbf{3 2}}$ & $c_{13}$ & 0.00 & 0.00 & -0.67 & -0.80 & -0.86 \\
\hline
\end{tabular}

Based on formula (5), the correlation degree of each level of bidding risk of wind farm construction project is calculated, as shown in formula (9)-(13).

$$
\begin{gathered}
\mathrm{K}_{1}(\mathrm{p})=\sum^{13} \omega_{\mathrm{i}} \mathrm{K}_{1}\left(\mathrm{v}_{\mathrm{i}}\right)=-0.338 \\
\mathrm{~K}_{2}(\mathrm{p})=\sum^{13} \omega_{\mathrm{i}} \mathrm{K}_{2}\left(\mathrm{v}_{\mathrm{i}}\right)=0.091 \\
\mathrm{~K}_{3}(\mathrm{p})=\sum^{13} \omega_{\mathrm{i}} \mathrm{K}_{3}\left(\mathrm{v}_{\mathrm{i}}\right)=-0.121 \\
\mathrm{~K}_{4}(\mathrm{p})=\sum^{13} \omega_{\mathrm{i}} \mathrm{K}_{4}\left(\mathrm{v}_{\mathrm{i}}\right)=-0.480 \\
\mathrm{~K}_{5}(\mathrm{p})=\sum^{13} \omega_{\mathrm{i}} \mathrm{K}_{5}\left(\mathrm{v}_{\mathrm{i}}\right)=-0.624
\end{gathered}
$$

\begin{tabular}{|c|c|c|c|c|c|}
\hline & \multicolumn{2}{|c|}{$\begin{array}{l}\text { Risks in the preparation stage of } \\
\text { bidding and tendering }\end{array}$} & \multirow{2}{*}{$\begin{array}{c}\text { Risks in the } \\
\text { implementation stage of } \\
\text { bidding and tendering } \\
\text { Management capability } \\
\text { risks }\end{array}$} & \multicolumn{2}{|c|}{$\begin{array}{l}\text { Risks in the bidding and } \\
\text { signing stage }\end{array}$} \\
\hline & $\begin{array}{l}\text { Technical } \\
\text { risks }\end{array}$ & $\begin{array}{c}\text { Social } \\
\text { environmental } \\
\text { risks }\end{array}$ & & $\begin{array}{c}\text { Assessment } \\
\text { risks }\end{array}$ & $\begin{array}{l}\text { Contract } \\
\text { risks }\end{array}$ \\
\hline$K_{1}(p)$ & -0.070 & -0.031 & -0.139 & -0.081 & -0.017 \\
\hline$K_{2}(p)$ & 0.004 & 0.03 & 0.090 & -0.024 & -0.008 \\
\hline$K_{3}(p)$ & -0.062 & -0.015 & -0.059 & 0.043 & -0.027 \\
\hline$K_{4}(p)$ & -0.105 & -0.046 & -0.188 & -0.078 & -0.064 \\
\hline$K_{5}(p)$ & -0.124 & -0.061 & -0.242 & -0.121 & -0.077 \\
\hline $\begin{array}{c}\text { Level three risk } \\
\text { indicator risk } \\
\text { level }\end{array}$ & $K_{2}$ & $K_{2}$ & $K_{2}$ & $K_{3}$ & $K_{2}$ \\
\hline $\begin{array}{l}\text { Risk rating for } \\
\text { secondary risk } \\
\text { indicators }\end{array}$ & \multicolumn{2}{|c|}{$K_{2}$} & $K_{2}$ & \multicolumn{2}{|c|}{$K_{2}$} \\
\hline
\end{tabular}

The correlation degree of each risk level of the bidding work obtained by the above calculation can be seen, $\mathrm{K}_{2}(\mathrm{p})=\max \left\{\mathrm{K}_{\mathrm{j}}(\mathrm{p})\right\}(\mathrm{j}=1,2,3,4,5)$, Therefore, the risk level of bidding risk work of the wind farm construction project is larger, which indicates that there is a great risk of bidding in the construction of this wind farm project. The risk levels for calculating each risk factor separately are shown in table 4 .

Table 4. Risk levels for each risk factor 
As can be seen from table 4, in the bidding preparation stage, bidding implementation stage, calibration contract stage of the risk level is two levels, the risk is greater: the impact of this wind farm construction project bidding risk ranking: from high to low in order of three stages of risk: the implementation stage of bidding is higher than the preparation stage of bidding, Bidding preparation stage is higher than the calibration contract stage.

\section{Conclusion}

In this paper, the risk of venture investment in wind farm construction project is evaluated. The research shows that: the bidding process of the wind farm construction project of Hebei Xintiandi Company is more risky, and the risk situation is sorted as: the risk of bidding implementation stage is greater than the risk of bidding preparation stage, the risk of bidding preparation stage is greater than the risk of calibration contract stage, and the preparation of the bidding stage of wind farm construction project is more adequate. , there is insufficient preparation for other stages, and compared with the multi-level fuzzy comprehensive evaluation method, the extensible matter element method does not have different evaluation principles, and can obtain more accurate evaluation results, which can provide effective support for decision-making.

\section{References}

Liang, X. Q. (2018). Practice and exploration of bidding for state-owned power generation Enterprises. Enterprise Reform and management, 23, 195-200.

Liu, Y. (2018). Common deficiencies and improvement in the management of electric power bidding. Low Carbon world, 33, 204-205.

Pichalai, C. (2015). Thailand Energy Efficiency Development Plan (2015-2036). Ministry of Energy.

Pimdee, P. (2017). Causal relationship model of Thai student energy conservation behavior. Journal of Sustainability Science and Management, 12(2), 218-227. Retrieved from https://tinyurl.com/yck59ppn

Pimdee, P., Thiengkamol, N., \& Thiengkamol, T. (2012). Psychological trait and situation affecting through inspiration of public mind to energy conservation behavior of undergraduate student. Mediterranean Journal of Social Sciences, 3(3), 81-87. https://doi.org/10.5901/mjss.2012.v2n3p81

Qin, H. Y. (2018). The prospect of wind power in China is limitless. Energy Intelligence Research, 10, 25-30.

Royal Institute Dictionary. (2011). Bangkok, Thailand: The Royal Society of Thailand.

Scherbaum, C., Popovich, P. M., \& Finlinson, S. (2008). Exploring individual-level factors related to employee energy-conservation behaviors at work. Journal of Applied Social Psychology, 38(3), 818-835. https://doi.org/10.1111/j.1559-1816.2007.00328.x

Staddon, S. C., Cycil, C., Goulden, M., Leygue, C., \& Spence, A. (2016). Intervening to change behaviour and save energy in the workplace: A systematic review of available evidence. Energy Research \& Social Science, 17, 30-51. https://doi.org/10.1016/j.erss.2016.03.027

Wang, B., Wang, X., Guo, D., Zhang, B., \& Wang, Z. (2018). Analysis of factors influencing residents' habitual energy-saving behaviour based on NAM and TPB models: Egoism or altruism? Energy Policy, 116, 68-77. https://doi.org/10.1016/j.enpol.2018.01.055

World Energy Outlook. (2016). Retrieved from https://tinyurl.com/oex5ctd

Yamane, T. (1973). Statistics: An introductory analysis (3rd ed.). New York, NY: Harper and Row.

\section{Copyrights}

Copyright for this article is retained by the author(s), with first publication rights granted to the journal.

This is an open-access article distributed under the terms and conditions of the Creative Commons Attribution license (http://creativecommons.org/licenses/by/4.0/). 